\title{
Distinct evolutionary histories of the DNA-A and DNA-B components of bipartite begomoviruses
}

Rob W Briddon ${ }^{1}$, Basavaprabhu L Patil², Basavaraj Bagewadi², Muhammad Shah Nawaz-ul-Rehman², Claude M Fauquet ${ }^{2^{*}}$

\begin{abstract}
Background: Viruses of the genus Begomovirus (family Geminiviridae) have genomes consisting of either one or two genomic components. The component of bipartite begomoviruses known as DNA-A is homologous to the genomes of all geminiviruses and encodes proteins required for replication, control of gene expression, overcoming host defenses, encapsidation and insect transmission. The second component, referred to as DNA-B, encodes two proteins with functions in intra- and intercellular movement in host plants. The origin of the DNA-B component remains unclear. The study described here was initiated to investigate the relationship between the DNA-A and DNA-B components of bipartite begomoviruses with a view to unraveling their evolutionary histories and providing information on the possible origin of the DNA-B component.

Results: Comparative phylogenetic and exhaustive pairwise sequence comparison of all DNA-A and DNA-B components of begomoviruses demonstrates that the two molecules have very distinct molecular evolutionary histories and likely are under very different evolutionary pressures. The analysis highlights that component exchange has played a far greater role in diversification of begomoviruses than previously suspected, although there are distinct differences in the apparent ability of different groups of viruses to utilize this "sexual" mechanism of genetic exchange. Additionally we explore the hypothesis that DNA-B originated as a satellite that was captured by the monopartite progenitor of all extant bipartite begomoviruses and subsequently evolved to become the integral (essential) genome component that we recognize today. The situation with present-day satellites associated with begomoviruses provides some clues to the processes and selection pressures that may have led to the "domestication" of a wild progenitor of the DNA-B component.

Conclusions: The analysis has highlighted the greater genetic variation of DNA-B components, in comparison to the DNA-A components, and that component exchange is more widespread than previously demonstrated and confined to viruses from the Old World. Although the vast majority of New World and some Old World begomoviruses show near perfect co-evolution of the DNA-A and DNA-B components, this is not the case for the majority of Old World viruses. Genetic differences between Old and New World begomoviruses and the cultivation of exotic crops in the Old World are likely factors that have led to this dichotomy.
\end{abstract}

\section{Background}

The family Geminiviridae consists of phytopathogenic viruses with characteristic twinned, quasi-isometric virions encapsidating genomes of circular single-stranded (ss)DNA. Taxonomically the geminiviruses are divided into four genera, three of which (Mastrevirus, Curtovirus and Topocuvirus) consist of viruses with monopartite genomes only. In contrast, the genus Begomovirus

\footnotetext{
* Correspondence: iltab@danforthcenter.org

ILTAB, Donald Danforth Plant Science Center, 975 North Warson Road, St Louis, MO, USA
}

consists of viruses with either monopartite or bipartite genomes [1]. Prior to 1990 all begomoviruses for which Koch's Postulates had been satisfied using cloned genomes were bipartite. Demonstration of the infectivity of a single component for two begomoviruses causing yellow leaf curl disease of tomato (now known as Tomato yellow leaf curl virus (TYLCV) and Tomato yellow leaf curl Sardinia virus (TYLCSV)) convinced the geminivirus community of the fact that begomoviruses with a single genomic component existed [2,3]. Since then more than 133 begomovirus species having monopartite
C Biomed Central

() 2010 Briddon et al; licensee BioMed Central Ltd. This is an Open Access article distributed under the terms of the Creative Commons Attribution License (http://creativecommons.org/licenses/by/2.0), which permits unrestricted use, distribution, and reproduction in any medium, provided the original work is properly cited. 
genomes have been identified and all originate from the Old World (OW). Remarkably, no monopartite begomoviruses native to the New World (NW) have been identified, although recently TYLCV was inadvertently introduced [4].

Within the last few years the vast majority of monopartite begomoviruses have been shown to associate with ssDNA satellites known as betasatellites. Betasatellites are sequence unrelated to their helper begomoviruses and depend on the helper viruses for replication, movement and encapsidation in plants and transmission between plants [5]. In addition, the majority of begomovirus-betasatellite complexes associate with a further class of ssDNA components for which the name alphasatellites has been proposed (formerly referred to as DNA 1; Briddon et al., manuscript in preparation). These are described as satellite-like (due to the fact that they are capable of autonomous replication in plant cells and by definition satellites require a helper virus for replication) and are sequence unrelated to their helper begomoviruses, which they require for movement in plants and transmission between plants [5]. Surprisingly alphasatellites are believed to have originated with another family of ssDNA containing viruses, the nanoviruses [6].

The two components of bipartite begomoviruses are referred to as DNA-A and DNA-B. DNA-A encompasses all virus-encoded functions required for DNA replication, control of gene expression, overcoming host defenses and encapsidation, whereas DNA-B encodes two proteins involved in intra- and intercellular movement [7]. The two components share little sequence identity with the exception of a $\sim 200$ nucleotide sequence with typically greater than $85 \%$ identity known as the common region (CR). The CR encompasses an absolutely conserved (among geminiviruses) hairpin structure containing, within the loop, the nonanucleotide sequence (TAATATTAC) that marks the origin of virion-strand DNA replication, and repeated sequences (known as "iterons") that are the recognition sequences for binding of the DNA-A-encoded replication-associated protein (Rep: a rolling-circle replication initiator protein that is the only virus-encoded product required for viral DNA replication) $[8,9]$. The CR thus functions to maintain the integrity of the divided genome, ensuring that replication of both components can be initiated by the DNA-A-encoded Rep [10-12].

Despite having a mechanism to maintain the integrity of their split genomes, component exchange, referred to as pseudo-recombination for begomoviruses, does occur [13-16]. In most cases the mechanism of capture is by a process known as "regulon grafting" wherein the DNAA component donates its $\mathrm{CR}$, by recombination, to the DNA-B being captured, resulting in a new dependent interaction between two components [17]. Similar origin of replication donation has also been shown to occur for the begomovirus-associated betasatellites although, for reasons that remain unclear, such pseudo-betasatellite molecules are at a selective disadvantage with respect to the parental betasatellite and appear not to be maintained [18].

Although the two components of the majority of bipartite begomoviruses have an obligate relationship, this is not true of all. Both Tomato yellow leaf curl Thailand virus (TYLCTHV) and Sri Lankan cassava mosaic virus(SLCMV) DNA-A components are able to induce symptomatic infections of the experimental host Nicotiana benthamiana in the absence of their cognate DNA-Bs $[17,19]$. These viruses likely represent evolutionary intermediates between monopartite and bipartite begomoviruses. The fact that TYLCTHV occurs in the field associated with either a DNA-B or a betasatellite is consistent with this hypothesis [20,21]. Although all isolates of SLCMV so far characterised are associated with a DNA-B, the potential for this virus to productively interact with a betasatellite has been demonstrated experimentally [17].

Many geminivirus infections are associated with smaller than unit length virus components that are deletion mutants, as reviewed by Patil and Dasguta [22]. These molecules are known as defective interfering (di) DNAs due to their capacity to interfere with virus infection, reducing virus DNA levels and symptom severity [23]. Surprisingly the diDNAs associated with bipartite begomoviruses are derived almost exclusively from the DNA-B component. It is unclear at this time whether this represents a preferential production of diDNAs from DNA-B or that diDNAs are produced equally from both components, but those derived from the DNA-B component are selectively maintained. Sunter et al. [24] showed that the super-coiled form of Tomato golden mosaic virus (TGMV) DNA-B is more sensitive to S1 nuclease digestion, indicative of a difference in the structure of the DNA-A and DNA-B components, which might partly explain the differential generation of diDNAs. The accumulation of three times the amount of DNA-B over DNA-A in a typical TGMV infected plant is a factor in the phenomenon [25]. It is possible that DNA-A derived sub-genomic molecules interfere excessively with virus replication and are thus selected against, although there is no evidence to support this hypothesis. There is however an example found in nature, where East African cassava mosaic virus (EACMV) accumulates DNA-A defective molecules and expressing milder symptoms, the accumulation of the diDNA-A is done at the expense of the DNA-B accumulation [26].

The ability of the DNA-A components of bipartite begomoviruses to spread in plants in the absence of 
DNA-B without inducing symptoms led to the hypothesis that symptoms are a feature of virus movement in plant tissues rather than replication [27]. Consistent with this hypothesis the MP or NSP proteins (but not both for a single species) have been shown to be symptom determinants [27-29].

Mutagenesis studies with the monopartite begomovirus TYLCV have shown that the CP, V2 and C4 proteins mediate nuclear shuttling $(\mathrm{CP})$ and cell-to-cell movement (V2, C4), respectively, the functions carried out by the DNA-B-encoded NSP and MP of bipartite viruses [30]. A major difference, however, was that these were unable to mediate movement through mesophyll and epidermal cells, with the consequence that TYLCV is essentially phloem restricted, in contrast to some bipartite begomoviruses. It is tempting to speculate that the lack of monopartite begomoviruses in the NW is due/related to the absence of the V2 gene.

Using pairwise sequence comparisons and phylogenetic studies we have compared the molecular diversity of the DNA-A and DNA-B components of bipartite begomoviruses. We show that there are distinct differences in the sequence distribution of the DNA-Bs of begomoviruses originating from the Old and New Worlds. Although the viruses from the NW behave in a uniform manner, the begomoviruses from the OW show a group/host specific distribution in pairwise sequence comparisons. The significance of these findings is discussed and the hypothesis that present-day begomovirus DNA-B components originated as satellites is explored.

\section{Results}

Phylogenetic analysis of geminivirus genome (or DNA-A component) sequences

A phylogenetic tree constructed from an alignment of the complete genome (or DNA-A component) sequences of 212 geminiviruses (one sequence representing each geminivirus species) is shown in Figure 1. This shows the grouping of begomoviruses according to either geographical origin or the host from which the viruses were isolated, as noted previously [31,32]. The begomoviruses from the OW segregate into clusters originating from Africa, India, Asia, and Japan. However, there is some overlap of the Asian and Indian clusters, likely due to the geographic continuity of these regions and consequent lack of barriers to spread the viruses and their vectors. In addition there are a growing number of viruses that do not fit neatly into these geographic or host based groupings that we shall henceforth refer to as "outsiders". These viruses originate from Indo-China, Indonesia and Australia.

The begomoviruses originating from the NW form a separate cluster from the OW viruses and group according to origin as either from Latin America or Meso
America. Closely related to the NW begomoviruses are two species originating from Vietnam isolated from Corchorus (hereafter referred to as "Corchovirus") $[33,34]$. Two further groups of viruses, those infecting a range of legumes originating from India and Southeast Asia (hereafter called "Legumovirus"), and a set of viruses isolated from Ipomoea spp. (particularly sweetpotato) originating from America, Asia and Europe (hereafter called "Sweepovirus") are distinct from, and basal to all other begomoviruses. This apparently anomalous position in the phylogenetic tree of these otherwise typical begomoviruses likely reflects a distinct evolutionary history. For the legumoviruses this has been suggested to be due to genetic isolation in their host species [15].

\section{PASC analysis of geminivirus genome (or DNA-A component) sequences}

The molecular diversity of virus sequences is conveniently analysed by pairwise sequence comparison (PASC) [35-39]. As of December 2006, there were 672 complete genome (or DNA-A component) sequences of geminiviruses available in the databases. Based on the presently applicable species demarcation criteria these belong to 212 geminivirus species [37]. A PASC analysis of the sequences reveals a multimodal distribution with six major peaks scattered between 19 and 100\% identity (Figure 2).

\section{Phylogenetic analysis of the DNA-A and DNA-B components of bipartite begomoviruses}

Of the 672 genome (or DNA-A component) sequences, 182 are of virus isolates of bipartite begomoviruses, belonging to 66 species, for which the cognate DNA-A and DNA-B (isolated from the same plant) sequences are available. Figure 3 is a comparison of the phylogenetic trees resulting from separate multiple alignments of the DNA-A and DNA-B sequences of selected single representatives of each of the 66 species.

The tree based on DNA-A component sequences shows the separation of viruses from the NW (with the corchoviruses) and the OW (Figure 3, left panel. For complete representation of the results summarized in Figure 3, see Panel A, Additional file 1 Figure S1: Phylogenetic trees constructed from an alignment of DNA-A (A) and DNA-B (B) component sequences of 182 bipartite begomoviruses). As in the earlier tree, the OW viruses cluster according to geographic origin or the host from which they were isolated. Two species of the "outsider" group segregate between, and are roughly equidistant to, the OW viruses and the legumoviruses. The two corchoviruses segregate with the NW viruses even though they originate from the OW (Vietnam). The tree based on DNA-B component sequences is similar to that obtained from DNA-A component 


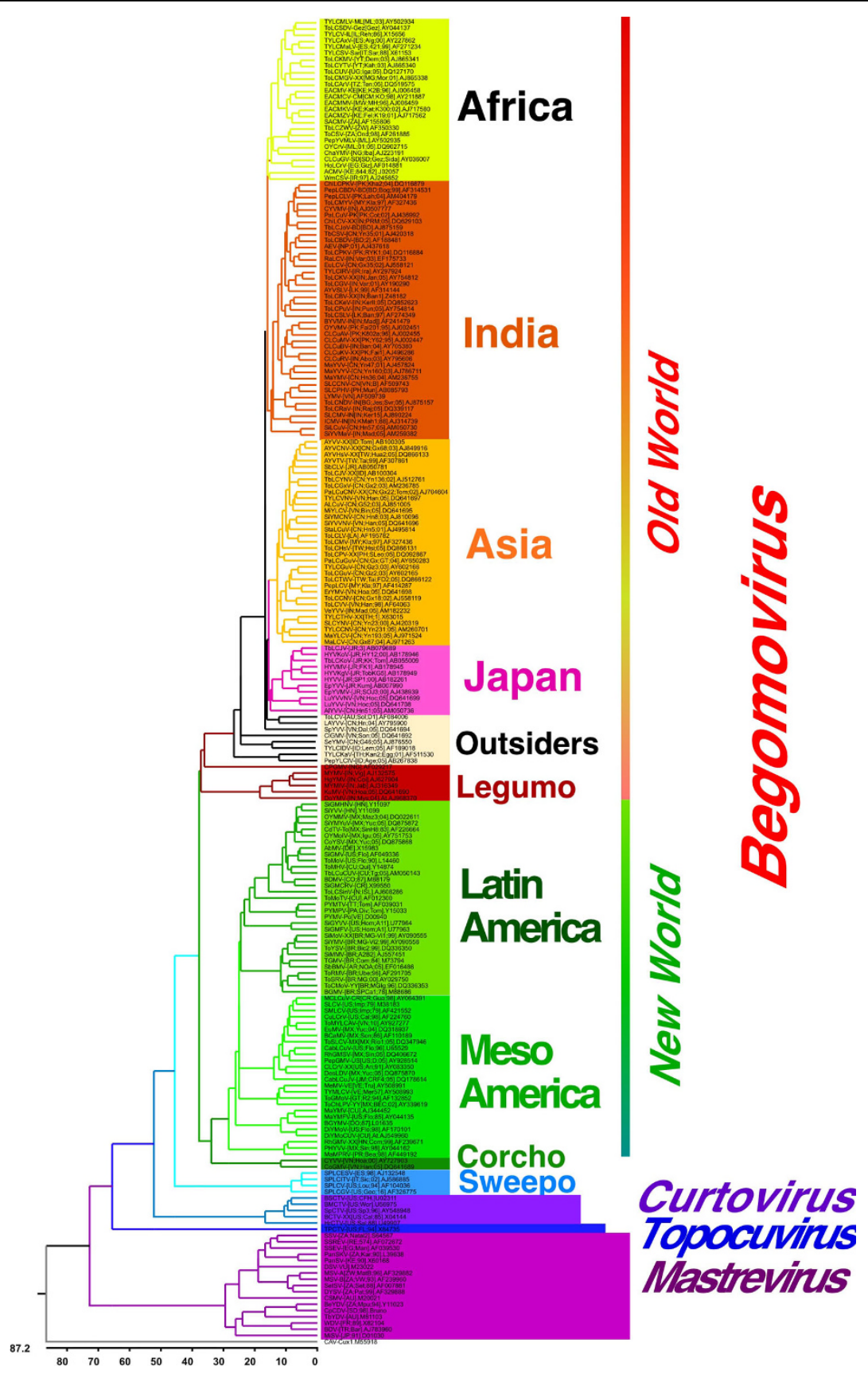

Figure 1 Phylogenetic tree constructed from an alignment of 212 DNA-A component sequences of geminiviruses. The sequences used are representative of the 212 geminivirus species recognized as of December 2006. The scale at the basis of the diagram is the pairwise distance expressed as percentage dissimilarity.

sequences, and shows the separation of viruses from the NW (with corchoviruses) from the OW viruses (Figure 3 , right panel). However, the members of the "outsiders" species that are distinct based on DNA-A sequences cluster with the viruses from Southeast Asia. Significantly, the ACMV DNA-B segregates with, and is basal to, the legumoviruses rather than associating with the DNA-Bs of the other viruses originating from Africa.
A phylogenetic tree based on all DNA-B components of begomoviruses for which a cognate DNA-A is available (182 DNA-B sequences) (see Panel B of Additional file 1 Figure S1: Phylogenetic trees constructed from an alignment of DNA-A (A) and DNA-B (B) component sequences of 182 bipartite begomoviruses) highlights the propensity of these viruses to exchange DNA-B components. For example, most MYMV and MYMIV isolates 


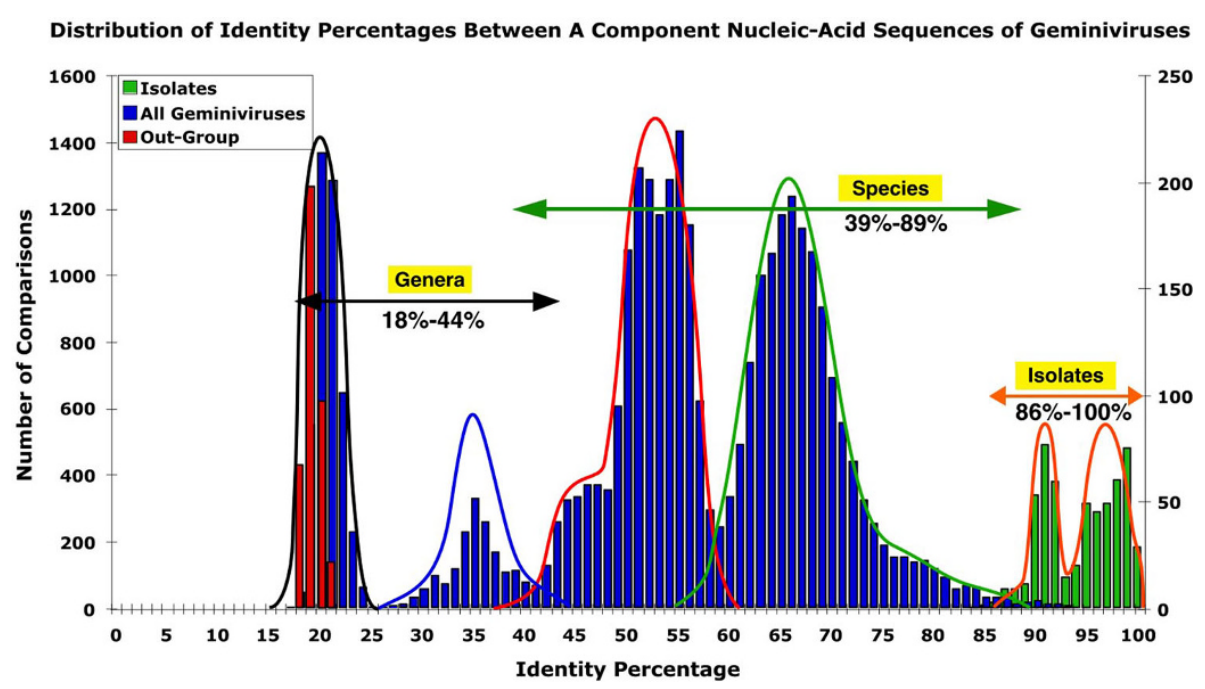

Figure 2 PASC analysis of 672 sequences of the complete genomes (or DNA-A components) of geminiviruses. Species comparisons are plotted on the left axis (blue bars) whereas isolate comparisons are plotted separately on the right axis (green bars). The out-group used is the sequence of Chicken anemia virus (\#M55918)(red bars).

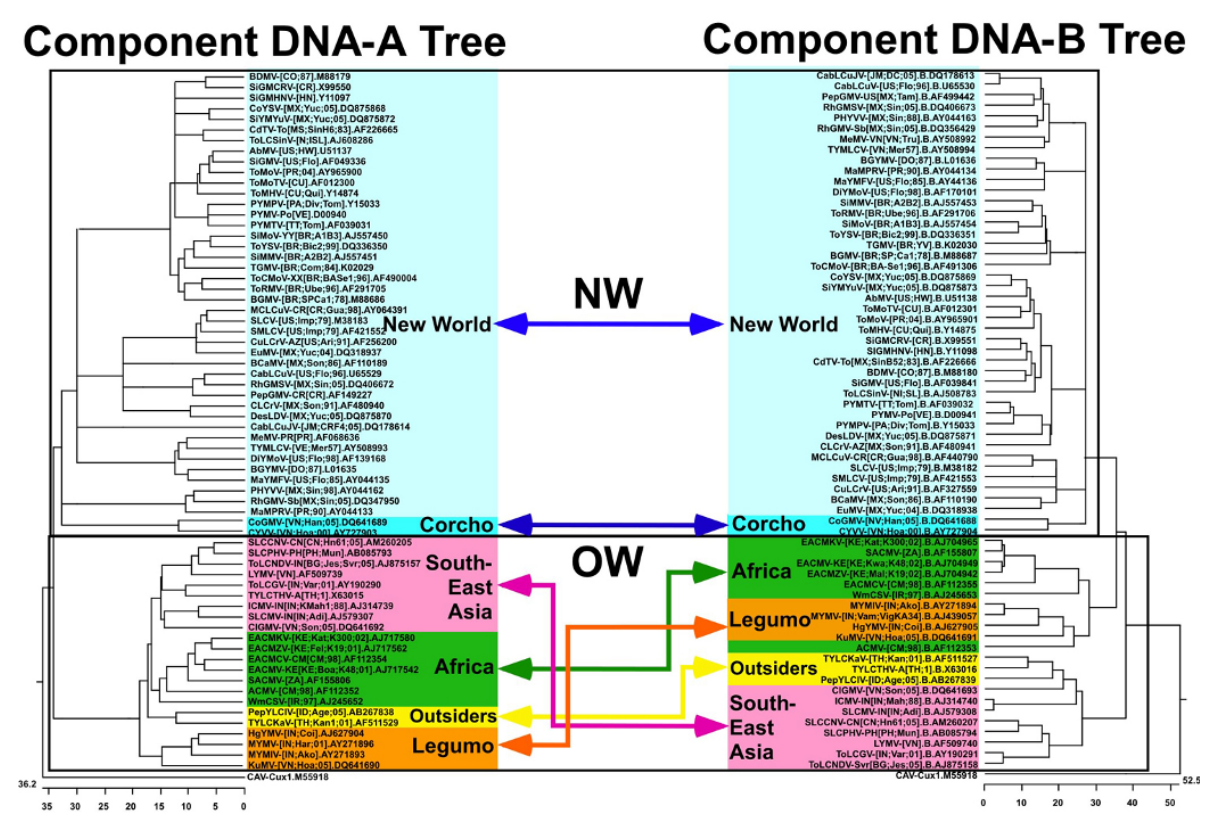

Figure 3 Phylogenetic trees derived from alignments of the components of bipartite begomoviruses. The tree based on the DNA-A sequences is shown on the left whereas that derived from the DNA-B sequences is shown on the right. Colours are used to highlight groups of sequences with distinct geographical origins. Branches having bootstrap values lower than $50 \%$ have been collapsed. The scale at the base of the diagram is the pairwise distance expressed as percentage dissimilarity.

trans-replicate a similar DNA-B component with the exception of five isolates of MYMV that have a distinct DNA-B, indicative of component exchange between these two species, as noted previously $[15,16,40]$. Similarly, all isolates of EACMV, EACMZV and SACMV have similar DNA-B components [14]: ToLCGV-[IN: Var:01] (AY190291) shares a DNA-B with ToLCNDV,
PuYVMV (AY184488) and SLCCNV-[VN:B]; and SLCMV and ICMV share a DNA-B [17]. Despite the fact that there are over twice the numbers of sequences available for bipartite begomoviruses originating from the NW, few examples [41] of component exchange have been detected in NW viruses. Thus, at least for bipartite begomoviruses originating from the OW, were 
species demarcation based upon DNA-B sequences, the range of species would look somewhat different than it does under the present classification system entirely based upon DNA-A sequences.

\section{PASC analysis of DNA-A component sequences of bipartite begomoviruses}

A PASC analysis reveals that the DNA-A component sequences of 182 bipartite begomoviruses are distributed in the range 50 to $100 \%$ nucleotide sequence identity (Figure 4). The pairs between 50 and $89 \%$ represent comparisons between members of species, while the pairs between 89 and $100 \%$ represent comparisons between isolates of the same species [37]. The OW virus species cluster into two major peaks between 55 and $70 \%$ and between 70 and $89 \%$, representing independent species and recombinant species respectively. It is noteworthy that the legumoviruses cluster in the lower values of the first peak (55-60\%). The NW viruses also cluster into two peaks at 51 to $67 \%$ and 67 to $89 \%$, with the OW-originating corchoviruses clustering in the lower range of the first peak (45-60\%). These two clusters represent different groups of viruses in each part of the world.

\section{PASC analysis of DNA-B component sequences of bipartite begomoviruses}

A PASC analysis reveals that the DNA-B component sequences of $\mathrm{OW}^{-}$begomoviruses are scattered over a wide area of the diversity spectrum (Figure 4 lower panel). The members of species of the OW begomoviruses cluster between 24 and $41 \%$ while the recombinants cluster between 45 and $73 \%$. The isolate comparisons cluster between 75 and 100\%. The NW (with corchoviruses) DNA-B components form two peaks. A peak at 44 to $70 \%$ corresponds to comparisons between members of species whereas the second, at 73 to $100 \%$, consists of comparisons between isolates. It is noteworthy that most of the species members from the OW do not cluster at the same identity percentage range as the members of the NW species. However, for both OW and NW viruses, the isolate comparisons fall

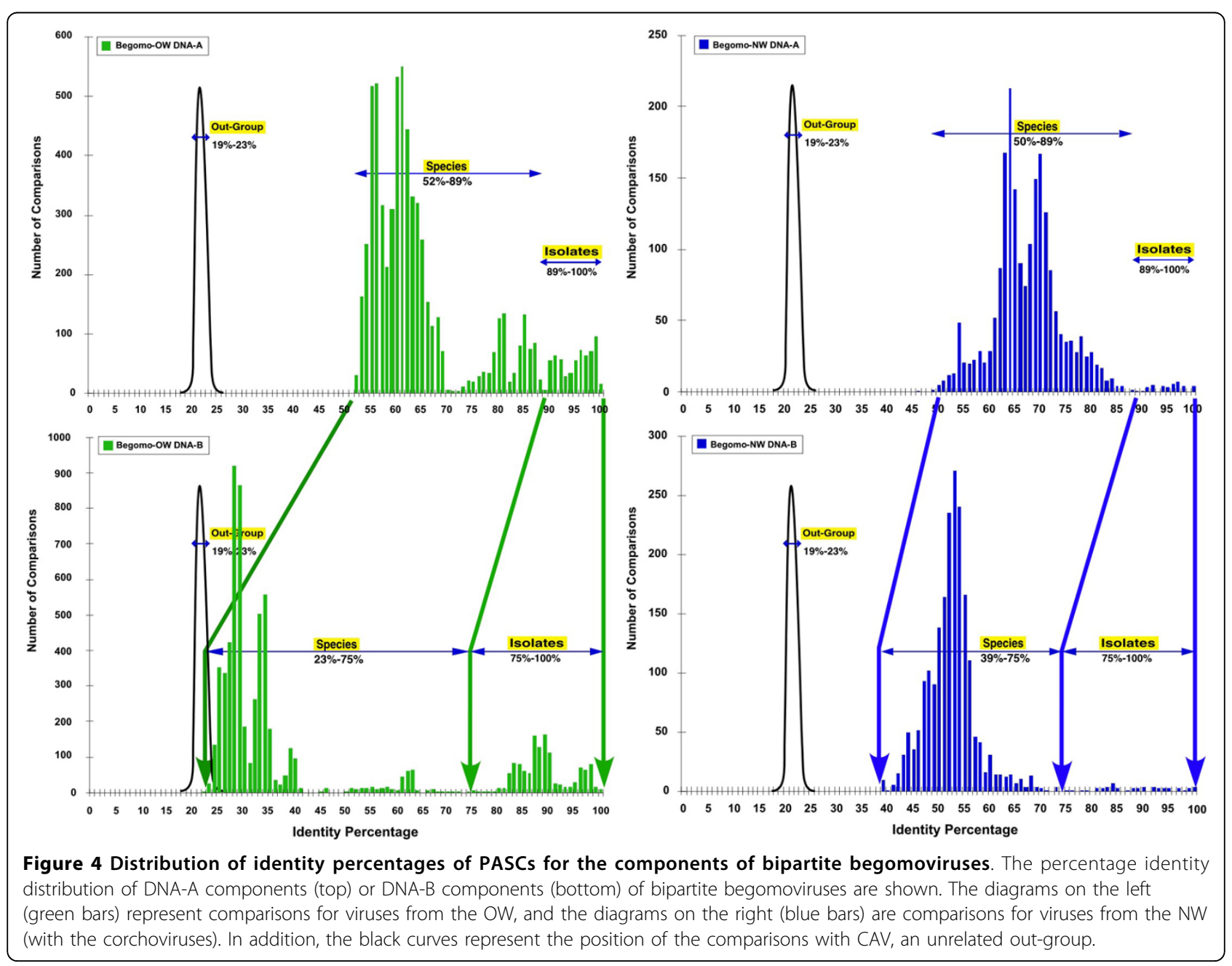


between 75 and $100 \%$. For simplicity, we considered the DNA-B "species" members as those associated with their cognate DNA-A species members according to the list of species recently defined [32]. Geminivirus species demarcation is based on both biological characteristics and sequence relatedness $[1,32]$. No separate classification system for DNA-B components is used, these being defined by their cognate DNA-A. This can lead to some confusion for the viruses that have exchanged DNA-B components.

\section{Comparison of the DNA-A and DNA-B component PASC distributions}

A comparison of the range of sequence distributions for the DNA-A and DNA-B components, as well as a comparison of the change in distributions (between the components) for the NW (with the corchoviruses) and OW begomoviruses is shown in Table 1. The DNA-A component PASC distribution occupies a smaller range of sequence identities (40-100\%) than the DNA-B distribution (24 to $100 \%$ ). The NW and OW species occupy roughly the same range of sequence identities (54-89\%). The values between 75 and $89 \%$ mostly represent recombinants that fill the gap between species and strains. The "isolate" peak for the DNA-A components divides into the "strains" at $87-93 \%$ and the "variants" between 94 and $100 \%$.

The DNA-B component pairwise distribution occupies a much larger range of sequence identities (24 to $100 \%$ ), which is about $16 \%$ greater than that of the DNA-A components. The species comparisons occupy a space between 24 and $73 \%$, which is comparable to the one occupied by species comparisons for the DNA-A component (49\%), except that it is much lower in sequence identity (about 16\% lower). The viruses of the species from the OW cluster in two distinct peaks, the first one from 24 to $42 \%$ and the second one from 53 to $73 \%$. The species from the NW, in contrast, form a single peak which is skewed and covers a wider range of sequence identities (44 to $73 \%$ ). In comparison to the isolates of component DNA-A, the isolates for component DNA-B also cover a greater range (up to $12 \%$ ).

A comparison of the shift values between the DNA-A and DNA-B component pairwise distributions (Table 1) shows an increasing shift from the high percentages
(90-100\%) down to the low percentages (24-40\%) with an increasing change from $3 \%$ to $\sim 16 \%$. However, for one of the two OW species, the shift is considerably larger (31 to $47 \%$ ).

\section{Co-evolution of the DNA-A and DNA-B components}

A total of 16,471 pairwise identity percentage values for comparisons of cognate DNA-A and DNA-B components of the 182 viruses considered were plotted on a scatter diagram (Figure 5). For the sake of clarity all comparisons $(>10,000)$ of OW with NW viruses have been omitted. These all fall in the low percentage range and are not informative for this analysis.

If the DNA-A and DNA-B components had been under the same evolutionary pressure, all the points on the graph (Figure 5) would align along the diagonal. However the analysis shows a difference between the distributions of species and isolates. The isolates are scattered along the diagonal (green oval, Figure 5), whereas the species points fall well below the diagonal (blue oval) indicating a greater diversity of the DNA-B components. Furthermore the majority of OW viruses cluster tightly at very low DNA-B percentage values (left red oval), as is also evident in Figure 6. This indicates that, although OW DNA-B components are more diverse (covering a greater range of percentage identities) the majority of OW comparisons group within a smaller range of both DNA-A and DNA-B percentage identity values. This, and the apparent shift in DNA-B diversity away from the diagonal between isolate and species comparisons (indicated by the white arrow, Figure 5), indicates a differential evolution between the DNA-A and DNA-B components.

\section{Co-evolution of the DNA-A and DNA-B components of the NW viruses}

Figure 6 (upper panel) shows a co-evolution analysis of the DNA-A and DNA-B components of NW viruses. There is great homogeneity in the shift of all the DNA$\mathrm{B}$ points relative to the DNA-A points, and the general trend is a change roughly parallel to the diagonal (indicated by the white arrows). Furthermore, it is interesting to note that there is a rough correlation between the phylogenetic tree organization and the percentage identity values for DNA-A and DNA-B component

Table 1 Comparison of DNA-A and DNA-B component PASC distributions.

\begin{tabular}{|c|c|c|c|c|c|c|}
\hline & Species & $\begin{array}{c}\text { OW } \\
\text { species }\end{array}$ & $\begin{array}{c}\text { NW } \\
\text { species }\end{array}$ & Isolates & Strains & Variants \\
\hline DNA-A components & $40-89 \%$ & $57-89 \%$ & $54-85 \%$ & $87-100 \%$ & $87-93 \%$ & $94-100 \%$ \\
\hline DNA-B components & $24-75 \%$ & $24-73 \%$ & $39-75 \%$ & $75-100 \%$ & $75-90 \%$ & $91-100 \%$ \\
\hline $\begin{array}{l}\text { Change in identity percentage range between the DNA-A and DNA -B } \\
\text { components }\end{array}$ & $16-14 \%$ & $33-16 \%$ & $15-10 \%$ & $12-0 \%$ & $12-3 \%$ & $3-0 \%$ \\
\hline
\end{tabular}




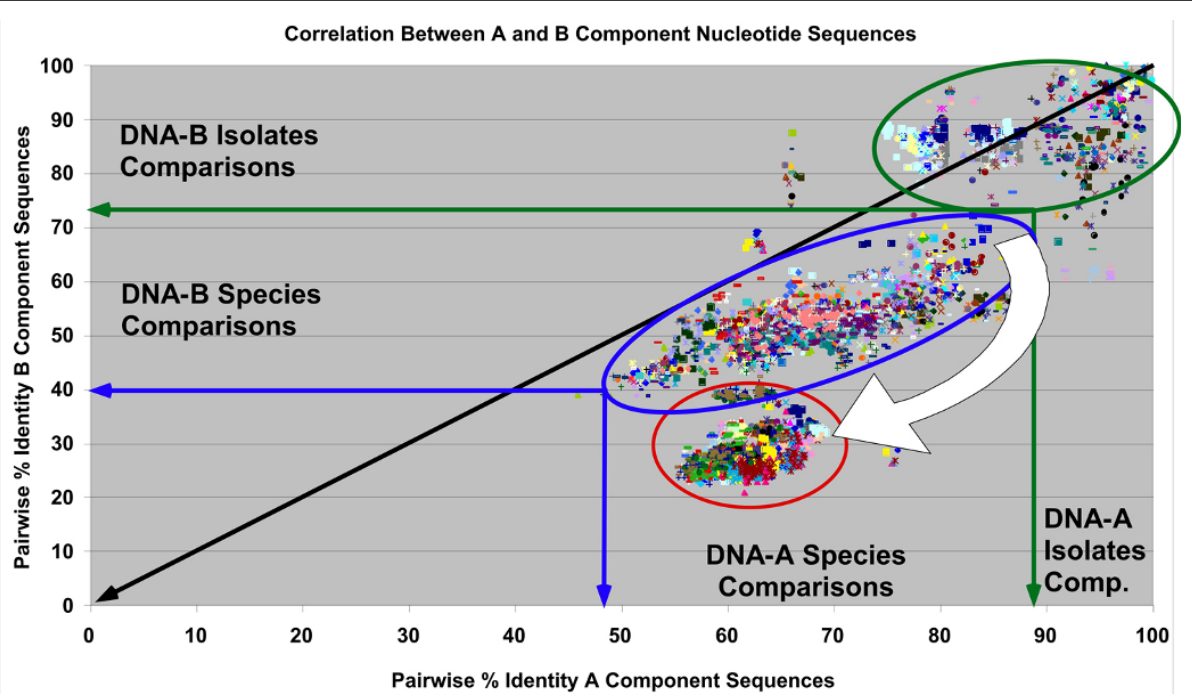

Figure 5 Scatter plot analysis of the pairwise percentage identity values for the components of bipartite begomoviruses. Scatter plots for cognate DNA-A ( $X$ axis) and DNA-B ( $Y$ axis) component sequences of bipartite begomoviruses are shown. For this analysis comparisons between NW and OW viruses were not included. The green oval (right) highlights isolate comparisons. The blue and red ovals highlight species representative's comparisons with most of the OW comparisons grouping at lower percentage identities (red oval). The white arrow is discussed in the text.

comparisons. The viruses belonging to the Chino del tomate virus cluster have the highest percentage identity values, while those belonging to the Squash leaf curl virus cluster have the lowest values of the NW viruses (data not shown) with only the corchoviruses having lower values (Figure 7, lower panel), mirroring their positions in the phylogenetic analysis relative to the NW viruses (Figure 1).

\section{Co-evolution of the DNA-A and DNA-B components of the OW viruses}

Figure 6 (lower panel) shows a co-evolution analysis of the DNA-A and DNA-B components of OW viruses. In contrast to the NW virus comparisons, the OW viruses show a dramatic shift of the species points (relative to the isolate points) to very low percentages (indicated by the curved arrow), where most of the data points occur in a very small DNA-B percentage range (24-40\%). There is also a change away from the diagonal for isolate and species comparisons and a vertical shift (indicated by the straight white arrows) for some of the DNA-B isolate data points, showing that the corresponding DNA-B components are simply exchanged between members of different species; thus with some DNA-A species having distinct DNA-B species as cognate DNA-B.

\section{Co-evolution of the DNA-A and DNA-B components of the OW legumoviruses}

Figure 7 (upper panel) shows a co-evolution analysis for the components of legumoviruses. These viruses behave like typical OW viruses with the percentage identity shifts parallel to the diagonal (white arrow parallel to the diagonal). However, this group shows extensive evidence of pseudo-recombination (vertical white arrows).

\section{Co-evolution of the DNA-A and DNA-B component pairwise comparisons of the OW Indo-China viruses}

Figure 7 (lower panel) shows the co-evolution of the DNA-A and DNA-B components of viruses isolated from Vietnam, Thailand and Indonesia that behave unusually in the phylogenetic analyses ("outsiders" in Figure 3). The Vietnamese viruses belonging to the NW cluster (CYVV and CoGMV) have a position typical of NW viruses, meaning a parallel shift to the diagonal, but very modest of about $10 \%$. Kudzu mosaic virus (KuMV), the legumovirus isolated from Vietnam, also has a typical legumovirus position but with a larger shift of $20 \%$, while the "outsiders", Pepper yellow leaf curl Indonesia virus (PepYLCIDV), Luffa yellow mosaic virus (LYMV) and Tomato yellow leaf curl Karnataka virus (TYLCKaV), behave like most of the OW viruses with a $35 \%$ shift.

\section{Taxonomy based on DNA-B component sequences}

Until 1990, the point at which the first monopartite begomovirus sequences were published, the classification of begomoviruses was based on both genomic components. At this point it was self-evident that the classification of begomoviruses could only be based on the DNA-A (or homolog thereof for monopartite viruses) component. The analysis presented here allows 

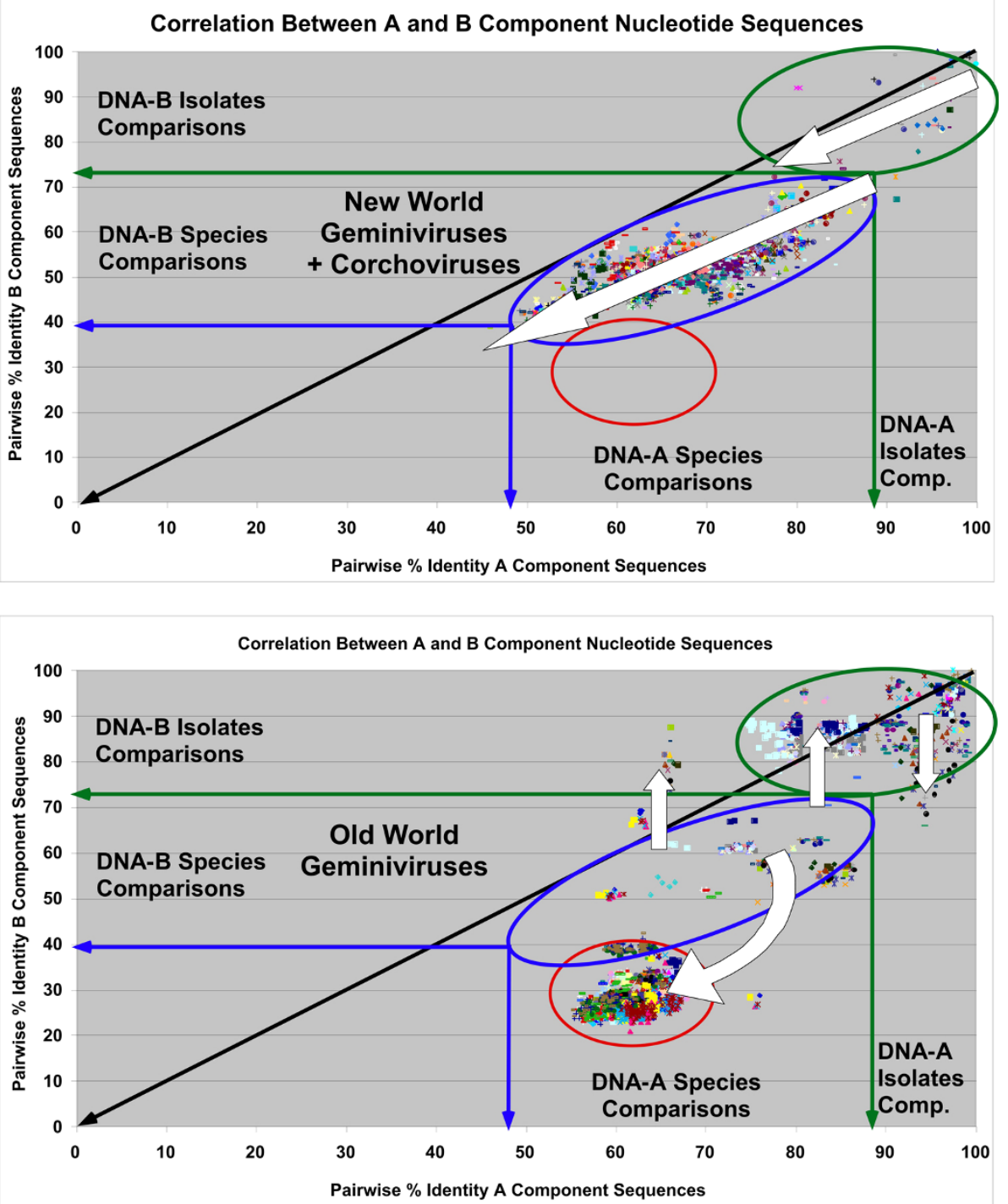

Figure 6 Scatter plot analysis of the pairwise percentage identity values for begomoviruses from OW and NW. Scatter plots for cognate DNA-A ( $X$ axis) and DNA-B ( $Y$ axis) component sequences of bipartite NW (with corchoviruses)(upper panel) and OW (lower panel) begomoviruses are shown. The green oval (right) highlights isolate comparisons. The blue and red ovals highlight species representative's comparisons with most of the OW comparisons grouping at lower percentage identities (red oval). The white arrows are discussed in the text.

us to examine, out of academic interest, what the classification of bipartite begomoviruses would be if it were based solely on the DNA-B component (Table 2). For 55 of the 65 species (based on DNA-A) represented, the classification would remain unchanged. Ten (DNA-A based) species would be downgraded to strains whereas one isolate would be upgraded to a new species. Thus the DNA-A-based classification system would remain $\sim 85 \%$ unchanged, providing good support for the present classification based solely on the sequences of the DNA-A components.

The analysis highlights the propensity of bipartite begomoviruses to exchange their DNA-B components (pseudo-recombination). One in six of the DNA-B components shows evidence of having been exchanged. For example, there are only seven begomovirus species in Africa and two in India that have been shown to cause cassava mosaic disease [42]. Based on DNA-B sequences there would be only four species. All the EACMV-like viruses (EACMV, EACMKV, EACMZV, EACMMV and SACMV), with the exception of EACMCV, would be considered a single species with four distinct strains. For the Asian viruses causing cassava mosaic disease, SLCMV and ICMV, there would be a single species with two strains. In addition there is not a simple correlation between what is a species based on DNA-A 


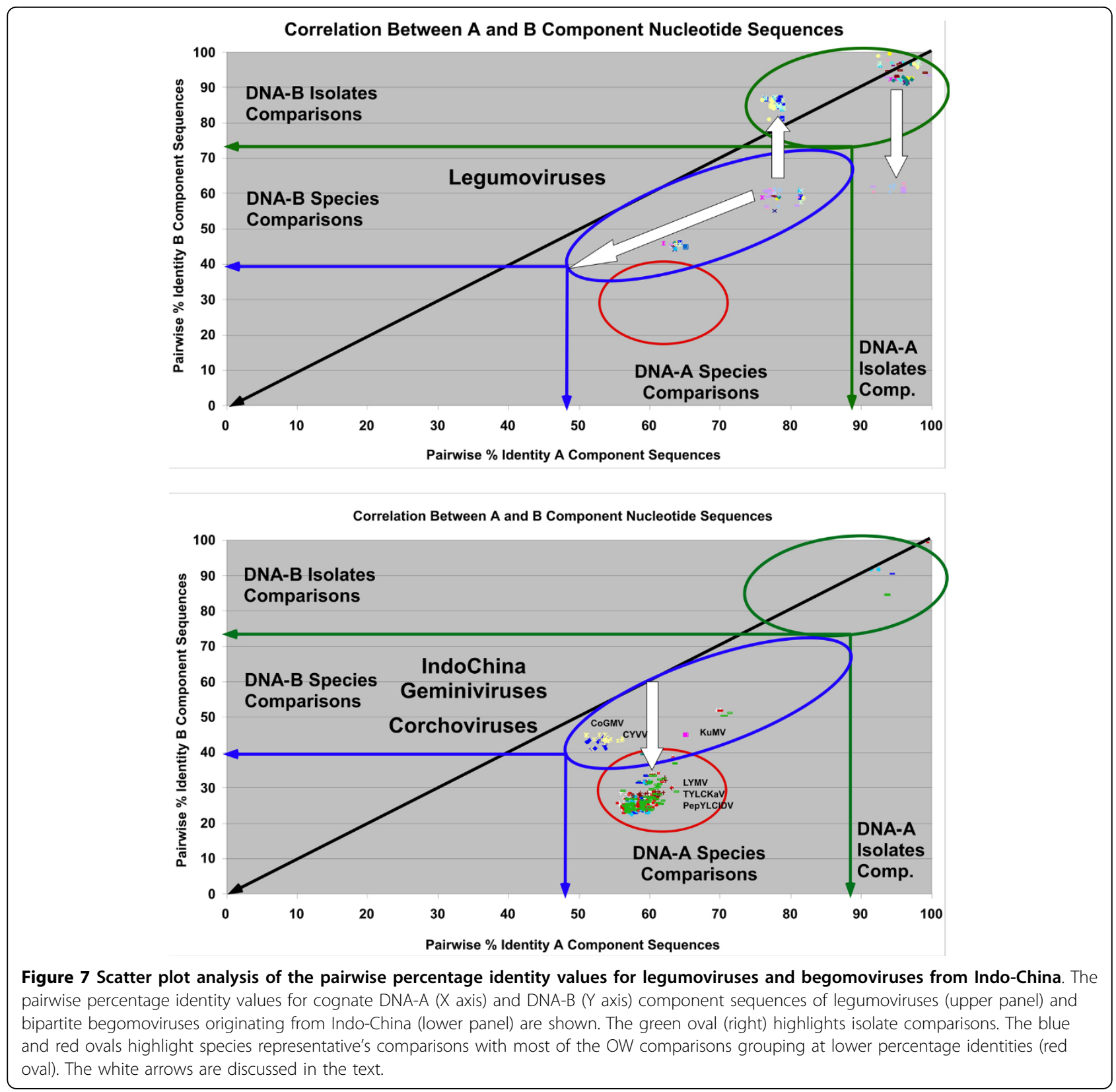

component sequence and what would be a strain based on DNA-B component sequence, due to component exchanges between species/strains. However, it is interesting to note that, apart from the example of Tomato chlorotic mottle virus (ToCMoV) from South America, all the strains within a species with the DNA-A-based classification remain in the same species with the DNAB component-based classification, indicating that exchanges occurred prior to diversification to the strain level. Thus component exchange possibly drives diversification of species into strains, which is not surprising since DNA-B components play a major role in host range determination [43].

\section{Discussion}

The geminiviruses as a whole have a very small range of genome (or genomic component) sizes; from $2550 \mathrm{nt}$ for Cotton leaf crumple virus (Begomovirus) DNA-B to $3080 \mathrm{nt}$ for the genome of Horseradish curly top virus (Curtovirus). This likely indicates that the capsid structure, consisting of 110 copies of a single protein (the $\mathrm{CP}$ ) arranged into a quasi-icosahedral (geminate) structure as 22 capsomeres [44,45], has a finite capacity for ssDNA. Monomeric (icosahedral) capsids are reported for most purified virus preparations and likely encapsidate half unit length ssDNA molecules [46]. Multimeric particles (mainly trimers and tetramers) occur only 
Table 2 Taxon changes for a taxonomy based on DNA-B.

\begin{tabular}{ll}
\hline DNA-A Component & DNA-B component \\
\hline 65 species & 55 species +1 New species $=85 \%$ \\
\hline Old World & $28 \%$ changes \\
\hline EACMV & SACMV \\
& EACMKV \\
& EACMZV \\
\hline SLCCNV & SLCPHV \\
\hline SLCMV & ICMV \\
\hline ToLCNDV & ToLCGV \\
\hline New World & $12 \%$ changes \\
\hline CabLCUV & CabLCuJV \\
\hline SiMoV & ToYSV \\
\hline ToCMoMGV & ToCMoV-[MG].Bseq.AY090556 \\
\hline PYMV & PYMTV \\
& PYMPV
\end{tabular}

List of species that would be downgraded to strains and strains that would be upgraded to species for a classification based on DNA-B component sequences.

infrequently, suggesting that they are not stable. In view of the congested nature of geminivirus genomes, with little if any scope for gaining additional functions (genes), the only option open to the monopartite progenitor of modern day bipartite begomoviruses was thus to expand genome size by adding an independently encapsidated DNA; either an additional genomic component or a satellite DNA.

The concept that geminiviruses have a modular arrangement is now well documented [47]. Thus certain elements of the genome are well adapted to work together, such as the MP and CP genes of mastreviruses [48] and the N-terminus of Rep (which interacts with the iterons that form part of the origin of replication [9,49-51]) and the origin of replication [47], and are thus less likely to be separated by recombination than distinct modules. It is clear here that DNA-B represents one such module, as evidenced by the relatively frequent exchange of this component for at least some of the groups of begomoviruses. Clearly maintaining this module as a separate unit in some circumstances facilitates its sexual exchange between distinct virus species and may represent an adaptation for diversification.

Why NW begomoviruses appear not to exchange DNA-B components with the high frequency demonstrated for their OW cousins is unclear. For this pseudo-recombination to occur, a single plant host cell would need to be infected by two viruses. It could also be conceivable that this could occur in the insect vector, assuming that the exchanged DNA-B can be transreplicated by its new DNA-A helper, since the two components of bipartite begomoviruses are encapsidated in separate geminate particles and there is no viral replication in vectors (precluding the recombination required for regulon grafting). The apparent absence of extensive component exchange in the NW could thus indicate that co-infections are (or at least were) not as frequent as in the OW. This, in turn, would suggest that the density of viruses in the NW is (or was) lower than in the OW. If, as has been suggested, begomoviruses were introduced into the NW only fairly recently, then a period of explosive speciation, following a limited introduction, could explain a low density of viruses. Alternatively, the low level of component exchange could be due to some mechanism (such as genetic isolation in a particular host due either to host specificity of the virus or the vector) that has prevented (or reduced) the frequency of co-infections. Experimentally NW begomoviruses appear to have few constraints to supporting pseudo-recombination, at least for related viruses $[52,53]$. However, there appear to be genetic differences between the (DNA-B-encoded) movement proteins of NW and OW begomoviruses. Frischmuth et al. [54] demonstrated that although the OW begomoviruses will mediate the systemic movement of the DNA-A components of NW viruses, the NW viruses cannot support the movement of the DNA-A components of OW begomoviruses - highlighting a further divergence between the NW and OW begomoviruses [55]. It is tempting to speculate that this difference is due to the absence of the V2 gene in NW viruses, as discussed later.

The similarities between the corchoviruses and begomoviruses occurring in the NW include the absence of the DNA-A-encoded V2 gene, the presence of a specific amino acid sequence motif in the $\mathrm{CP}$, as well as the cosegregation of both components in phylogenetic analyses $[33,34]$. In the analyses conducted here the corchoviruses, originating from Vietnam, behave in all respects like the NW begomoviruses and this is consistent with the earlier reports. Ha et al. [33] suggested that the most likely explanation for this apparent presence of a NW-like virus in the OW was that all NW begomoviruses originated from a fairly recent introduction of begomoviruses into the NW, possibly by Chinese traders or much earlier by the Asian ancestors of the AmeroIndians. Certainly the relatively low level of diversity of the NW viruses is consistent with this hypothesis. However, the introduction would have needed to have been very limited, thus not include the monopartite and monopartite betasatellite-associated begomovirues. If this is the case, then it is possible that, at the time of the introduction, the NW-like begomoviruses were more widespread than at present (we note that recently CoGMV has been shown to occur in Corchorus in India [56]), or that the monopartite and monopartite betasatellite-associated begomoviruses evolved after the introduction - which seems unlikely - or were very limited in 
their geographic distribution at least until recently. It is clear that many questions about the origin of NW begomoviruses and their relationship to the OW viruses remain to be answered.

It has previously been argued that legumoviruses are (or at least were) genetically isolated in their legume hosts [15], as evidenced by the absence of recombination with other, non-leguminous begomoviruses. Possibly the corchoviruses have similarly been genetically isolated, preventing interaction with the more diverse begomoviruses infecting other plant species and shielding their unique NW-like characters from change. Why the corchoviruses and NW begomoviruses should show such a constrained and uniform pattern of genetic variation is a more vexing question. The possibility that the absence of the V2 gene is somehow responsible for this phenomenon should be investigated experimentally. The precise function of the V2 protein remains unclear although various investigations have shown it to have possible virus movement and suppression of gene silencing activity $[30,57,58]$. It is thus possible that the absence of these (or other as yet unknown) functions constrain variability. An investigation of the host-range of the corchoviruses might provide some answers since, if these viruses are genetically isolated (presumably in their natural host jute [Corchorus capsularis]), the absence of V2 may be an adaptation to this host.

From the comparisons of the pairwise distributions of the DNA-A and DNA-B component sequences of begomoviruses, it is evident that they have followed different evolutionary paths and have experienced different evolutionary pressures, or have responded differently to the evolutionary pressures. The DNA-B components show a much wider range of molecular diversity than the DNAA components [59]. The reasons for this are unclear. Possibly the DNA-B component, by virtue of it not encoding overlapping genes, has a greater capacity for variation. The ranges of interactions this component's gene products undergo may be fewer or may be less constraining. The highly specialized nature of the DNA$\mathrm{B}$ component gene products, which interact with plasmodesmata and nuclear pores to mediate cell-to-cell and long distance movement, may allow for a greater range of variation than is possible with the DNA-A component which is more modular and has more cis- (including transactivation, Rep-iteron recognition, Rep-REn interaction) and trans-interactions (including transactivation, Rep-iteron recognition, $\mathrm{CP}$-vector interaction) to maintain. Alternatively, the differences may indicate that the genomes of the majority of OW bipartite begomoviruses result from component exchange. It is noticeable that there are relatively few bipartite begomoviruses in the OW, or at least only few have been identified, and the majority of the ones with unusual behaviour in the PASC analyses are isolated from introduced crops (including cassava, tomato and peppers) whereas those that might be considered as being isolated from native species (such as Corchorus and the legumeinfecting viruses), and thus might be considered more ancient, have a behaviour more in line with those from the NW and more in-line with what would be expected were the two components under similar evolutionary pressures. What the PASC analysis may be showing could thus be the result of relatively young DNA-ADNA-B interactions, for which the DNA B component has yet to be fully shaped by the relationship.

The analyses of bipartite begomovirus component sequences indicate that our present classification system, based entirely on their DNA-A components, holds for the majority of viruses were the system instead to be based on DNA-B components; the exceptions to this being the cases where pseudo-recombination has occurred. There would thus be little to gain from including DNA-B sequences at the species level. Possibly this character should be relegated to the strain level; thus two isolates of a species with distinct DNA-Bs might be designated distinct strains. In view of the fact that DNA-B components play a significant role in host range determination, this may be a desirable option. However, although this might be useful in some cases, it would require a separate classification system for the DNA-B components which might prove too cumbersome.

This overall very good similarity shows that most of the DNA-As and DNA-Bs of bipartite geminiviruses of the same species have been associated for a very long time and had the same type of evolutionary pressure. Nevertheless, a significant number of viruses show evidence of component exchange by a mechanism known as regulon grafting. The fact that geminiviruses have the possibility to recombine easily $[17,18,60-65]$ increases the chances of a DNA-A component CR introgression in a non-related DNA-B component, to make that DNA-B component dependent on the replication of the cognate DNA-A component. There is evidence of the natural occurrence of the recombination between the helper begomovirus genomes and their betasatellite molecules that supports this hypothesis $[18,66]$. There is also the sequence analysis evidence for PYMV isolates (from Panama, Venezuela and Trinidad) where the same CR has been introgressed simultaneously in DNA-A and DNA-B components having over all very different sequences (C. Fauquet, unpublished results). In this latter case a dual recombination had to occur at the same time to recreate a viable strict bipartite geminivirus, and this happened at least two times, once with the PYMV isolate from Trinidad and Tobago, and once with the PYMPV isolate from Panama. It is conceivable that the synergism between two molecules such as a geminivirus 
and a betasatellite molecule based on mutual biological gain, can be maintained over very long periods of time [67], but it is also more intuitively acceptable that the physical interdependence of replication between two molecules be a more stringent level of interdependence in virus evolution. It is interesting to note that geminivirus satellites have so far been found almost exclusively with monopartite begomoviruses. The exceptions are TYLCTHV, which is an unusual virus with a DNA-A which is infectious to plants (experimentally in the absence of DNA-B) but occurs in the field with either a DNA-B or a DNA- $\beta[19,68]$, ToLCNDV and MYMIV [69]; the nature of the interaction of the latter two viruses with betasatellites has not been investigated. Possibly this indicates that the presence of a DNA-B component prevents/interferes with the interaction of the DNA-A component with a satellite.

Comparisons of the PASC distributions of DNA-A and DNA-B components show a fundamentally different behaviour between the NW and OW viruses. NW viruses show a very homogenous shift of their DNA-B component sequences towards a lower percentage of identity, paralleling the diagonal that represents a quasiperfect co-evolution. In contrast, the OW viruses fall into two groups with distinct behaviours. For most OW viruses there is a dramatic shift (30 to $47 \%$ ) in the PASC percentage identity values between DNA-A and DNA-B components, bringing the values close to comparison with a random sequence. For a small number of OW viruses the change is more modest $( \pm 10 \%)$, similar to that seen with the NW viruses. This may indicate that some of the OW viruses have been under entirely different selection pressures. The most obvious difference between OW and NW begomoviruses is the absence of the AV2 gene in the latter. The AV2 protein has been shown to play a role in the movement of begomoviruses [57] and possibly also, either directly or indirectly, in the expression of the CP [70], which is itself involved in movement. It is thus possible that $\mathrm{OW}$ begomoviruses, having an AV2, have more flexibility with regard to movement in planta. As well as allowing them to, in some cases, spread and cause disease in the absence of a DNA-B, it may allow them to additionally interact with other molecules, such as betasatellites and, more readily than for the NW viruses, the DNA-B components of other species. However, it is difficult to see, knowing what we do about the functions encoded by AV2, how this gene might predispose a virus to component exchange.

Satellites are a common feature of a number of RNA viruses and also begomoviruses [5,71]. These molecules are classically defined as viruses or nucleic acids that depend on a helper virus for replication, are dispensable for the replication of the helper virus, and lack any appreciable sequence similarity to the helper virus' genome [72]. With the exception of the CR, begomovirus DNA-B components are essentially sequence unrelated to their cognate DNA-A components. Thus DNA-B components satisfy all except one of the criteria of satellites. The presently accepted hypothesis for the origin of DNA-B contends that it originated by component duplication of the DNA-A, followed by gain of a new gene (the movement protein encoded in the complementarysense) from an unknown source and possible divergence of the CP to become the nuclear shuttle protein (NSP; encoded in the virion-sense). Although Kikuno et al. [73] reported some similarity between the amino acid sequences of the CP and NSP sequences for ACMV, this has not been borne-out by modern sequence analysis software applied to either ACMV or the much larger sample set of bipartite begomovirus sequences now available (C.M. Fauquet, unpublished results). However, an equally plausible hypothesis is that the begomovirus DNA-B component originated as a satellite captured by the monopartite progenitor of all bipartite begomoviruses in the same way that betasatellites and alphasatellites were. Although the origins of the betasatellites remain uncertain, the alphasatellites almost certainly originated with the nanoviruses, which themselves are helper viruses of a related class of alphasatellites [6]. The satellite progenitor of modern DNA-B components would have needed to provide its helper begomoviruses with some selective advantage for it to be maintained. In most cases the betasatellites allow their helper begomoviruses to productively infect hosts to which they are otherwise only poorly infectious $[74,75]$, either by overcoming host defenses [76] or possibly by providing additional movement functions [77]. It is thus possible that the selective advantage provided by the early DNA-B was more efficient movement in plants, possibly in the form of the MP. The satellite would then have been domesticated into a bona fide genome component by regulon grafting from DNA-A (for which there is extensive evidence in both the DNA-Bs and betasatellites, as detailed earlier) and possible gene duplication (of the $\mathrm{CP}$ to yield the NSP) leading to the DNA-B component we recognize today.

For the bipartite begomoviruses the genes encoded by DNA-B have been shown to play a major part in controlling genome size. Unit length $(\sim 2800 \mathrm{nt})$ viral DNA is moved cell-to-cell more effectively than larger molecules and larger DNA molecules undergo deletion to restore approximately unit size length [78]. This size selection is mediated by MP which has evolved to usurp the non-cell autonomous RNA trafficking pathway through plasmodesmata. The mechanism for maintaining genome size of monopartite viruses is less clear. Frischmuth et al. [46] have shown, for the bipartite 
begomovirus ACMV, that genome size is a determining factor in particle multiplicity; thus half unit length molecules (such as diDNAs and probably betasatellites and alphasatellites) are encapsidated in monomeric (icosahedral) particles whereas unit length molecules are encapsidated in geminate particles and larger molecules in multimeric particles. The relative rarity with which multimeric particles are encountered possibly suggests that these are unstable. Thus packaging constraints may be an important control of geminivirus genome size, particularly for the monopartite viruses. For the begomovirus-associated beta- and alphasatellites there is some circumstantial evidence of a need to satisfy a size constraint. The presence in both of an adenine (A)-rich stretch of sequence has been taken to signify an increase in size over the progenitor component (the only real evidence for this being the lack of a similar A-rich sequence in the smaller nanovirus components, the closest relatives of the alphasatellites [65,79], although this does not explain why the sequence needs to be rich in adenine). The evolutionary maintenance by DNA-B components of a size close to that of their DNA-A "helper", when it is clear that a half unit length size can be accommodated, may indicate either that there are coding constraints to having the MP and NSP in overlapping reading frames (which would be required were they to be encoded by a half unit length molecule), or more likely that there is a need for strict spatial and temporal control of the genes during infection, which is possible when they are under the control of distinct promoters (the NSP gene being inducible by TrAP [80]). Little is known about the control of expression of the $\beta \mathrm{C} 1$ gene encoded by betasatellites. Available evidence suggests it is controlled by a strong promoter which is constitutive and phloem specific $[81,82]$.

\section{Conclusion}

The analysis shows that the DNA-B components of bipartite begomoviruses are far more diverse than their DNA-A partners. This may be due to the DNA-B component being less congested (encoding fewer functions and thus being more permissive of variation), the DNA$\mathrm{B}$ component evolving exclusively in response to the host (whereas the DNA-A has to additionally maintain interaction with the arthropod vector) or, as we propose for the first time, that DNA-B has an origin that is distinct from DNA-A (possibly originating as a captured and domesticated satellite). The most likely explanation for the difference is that a combination of these factors is responsible. Pseudorecombination is shown to have occurred much more frequently than previously recognized and to be a property almost exclusively exhibited by OW begomoviruses. Although the evidence is only circumstantial, the presence in OW begomoviruses of an additional movement function (the V2 gene) may be the factor facilitating this phenomenon. The co-evolution study for the components of the genomes of bipartite begomoviruses highlights distinct differences between the majority of OW viruses and a group that includes all the NW begomoviruses and a small number of OW viruses. The latter group shows near perfect coevolution of their DNA-A and DNA-B components whereas for the majority of the OW viruses this is not the case. This indicates that for the majority of OW bipartite begomoviruses the DNA-A and DNA-B components have been under distinct evolutionary pressures or have responded differently to the pressure. Since the majority of OW begomoviruses with uniform DNA-A/ DNA-B behaviour occur in native plant species, whereas the ones with unusual behaviour (thus most of the OW viruses) occur in introduced species, it is possible that this dichotomy is due to the host and due to pesudorecombination, suggesting a recent and immature DNAA/DNA-B interaction.

\section{Methods}

\section{Sequences analysed}

The sequences of the genomes (or DNA-A components) of 389 geminiviruses were downloaded from GenBank. The dataset contains the full-length sequences of the cognate DNA-A and DNA-B components of 182 bipartite begomoviruses. For several sequences corrections have been made as indicated previously [31]. For brevity only the standardised virus acronyms will be used $[1,32]$.

\section{Pairwise sequence comparison and phylogenetic analysis} All possible pairwise sequence comparison (PASC) percentage identities were plotted as frequency distributions to examine the distributions within and between taxa/ subgroups [83].

Sequences were aligned using the Clustal V method of aligning multiple sequences using MegAlign (v. 3.11) available in the Lasergene sequence analysis package (v.1.02 for the Apple Computer; DNASTAR Inc.). A random sequence of equal length and composition was included in all alignments to show pairwise percent identities that are not significantly different from random identity. For phylogenetic studies, the sequence of Chicken anemia virus (CAV; accession number M55918), a member of the genus Circovirus in the family Circoviridae, was used as an out-group.

Phylogenetic analyses were conducted using the cladistic parsimony method and the program PAUP (version 3.1.1 [84]). Optimum trees were obtained with the heuristic method using the tree-bisection-reconnection branch-swapping option. One hundred bootstrap replications were performed to place confidence estimates on groups contained in the most parsimonious tree. 
Phylogenetic analyses were also conducted using the UPGMA distance matrix and neighborhood joining method available with the MegAlign program. In this case a preliminary phylogeny is derived from the distance between pairs of input sequences and the application of the UPGMA algorithm that guides the alignment of ancestral sequences [85]. The final phylogeny was obtained by applying the neighborhood joining method to the distance and alignment data [86]. The trees generated by both PAUP and MegAlign were nearly identi$\mathrm{cal}$, and the tree presented here was generated using the MegAlign program.

Additional file 1: Figure $\mathbf{S 1}$. Phylogenetic trees constructed from an alignment of DNA-A (A) and DNAB (B) component sequences of 182 bipartite begomoviruses. The trees were constructed from 2947 informative sites for the DNA-A alignment and 3223 informative sites for the DNA-B alignment. For brevity only the standardised virus acronyms are used $[1,32]$ complemented by the database accession numbers. Sequences were aligned using the Clustal $V$ method of aligning multiple sequences using MegAlign (v. 3.11) available in the Lasergene sequence analysis package (v.1.02 for the Apple Computer; DNASTAR Inc.).

Phylogenetic analyses were conducted using the UPGMA distance matrix and neighborhood joining method available with the MegAlign program. The dashed branches indicate a bootstrap value below $50 \%$ and the scale below the tree indicates the distance between sequences.

\section{Acknowledgements}

R.W.B. is supported by the Higher Education Commission (HEC) of the Government of Pakistan under the "Foreign Faculty Hiring Program". This work was supported by the National Academy of Sciences' Pakistan-US Science and Technology Cooperative Program, Contract PGA-7251-05-007 (S. M. N.) and by the Donald Danforth Plant Science Center for the other authors.

\section{Author details}

${ }^{1}$ National Institute for Biotechnology and Genetic Engineering (NIBGE), Faisalabad, Pakistan. ${ }^{2}$ ILTAB, Donald Danforth Plant Science Center, 975 North Warson Road, St Louis, MO, USA. ${ }^{3}$ Department of Plant Pathology, University of Kentucky, Lexington, KY, USA.

\section{Authors' contributions}

$\mathrm{RB}$ wrote the paper and contributed to the Discussion. BP contributed to the Introduction, Discussion and Results. BB contributed to the elaboration of the paper. MSN downloaded sequences, made their phylogenies, calculated similarity percentages of different DNA-B components and contributed to the elaboration of the paper. CMF conceived of the study, performed the sequence and phylogenetic analyses, created the figures, wrote the paper and contributed to the Discussion. All authors have read and approved the final manuscript.

\section{Competing interests}

The authors declare that they have no competing interests.

Received: 18 June 2009 Accepted: 8 April 2010 Published: 8 April 2010

\section{References}

1. Stanley J, Bisaro DM, Briddon RW, Brown JK, Fauquet CM, Harrison BD, Rybicki EP, Stenger DC: Geminiviridae. Virus Taxonomy. VIllth Report of the International Committee on Taxonomy of Viruses London: Elsevier/Academic PressFauquet C, Mayo M, Maniloff J, Desselberger U, Ball L 2005, 301-326.

2. Navot N, Pichersky E, Zeidan M, Zamir D, Czosnek H: Tomato yellow leaf curl virus: a whitefly-transmitted geminivirus with a single genomic component. Virology 1991, 185:151-161.
3. Kheyr-Pour A, Bendahmane M, Matzeit V, Accotto GP, Crespi S, Gronenborn B: Tomato yellow leaf curl virus from Sardinia is a whiteflytransmitted monopartite geminivirus. Nucleic Acids Res 1991, 19:6763-6769.

4. Polston J, McGovern R, Brown L: Introduction of tomato yellow leaf curl virus in Florida and implications for the spread of this and other geminiviruses of tomato. Plant Dis 1999, 83:984-988.

5. Briddon RW, Stanley J: Sub-viral agents associated with plant-infecting single-stranded DNA viruses. Virology 2006, 344:198-210.

6. Gronenborn B: Nanoviruses: genome organisation and protein function. Vet Microbiol 2004, 98:103-109.

7. Sanderfoot AA, Lazarowitz SG: Getting it together in plant virus movement: cooperative interactions between bipartite geminivirus movement proteins. Trends Cell Biol 1996, 6:353-358.

8. Hanley-Bowdoin L, Settlage SB, Orozco BM, Nagar S, Robertson D: Geminviruses: models for plant DNA replication, transcription, and cell cycle regulation. Crit Rev Plant Sci 1999, 18:71-106.

9. Argüello-Astorga GR, Ruiz-Medrano R: An iteron-related domain is associated to motif 1 in the replication proteins of geminiviruses: identification of potential interacting amino acid-base pairs by a comparative approach. Arch Virol 2001, 146:1465-1485.

10. Elmer JS, Brand L, Sunter G, Gardiner WE, Bisaro DM, Rogers SG: Genetic analysis of the tomato golden mosaic virus. II. The product of the AL1 coding sequence is required for replication. Nucleic Acids Res 1988, 16:7043-7060.

11. Argüello-Astorga GR, Guevara-González RG, Herrera-Estrella LR, RiveraBustamante RF: Geminivirus replication origins have a group-specific organization of iterative elements: a model for replication. Virology 1994, 203:90-100.

12. Fontes EP, Eagle PA, Sipe PS, Luckow VA, Hanley-Bowdoin L: Interaction between a geminivirus replication protein and origin DNA is essential for viral replication. J Biol Chem 1994, 269:8459-8465.

13. Pita JS, Fondong VN, Sangare A, Otim-Nape GW, Ogwal S, Fauquet CM: Recombination, pseudorecombination and synergism of geminiviruses are determinant keys to the epidemic of severe cassava mosaic disease in Uganda. J Gen Virol 2001, 82:655-665.

14. Bull SE, Briddon RW, Sserubombwe WS, Ngugi K, Markham PG, Stanley J: Genetic diversity and phylogeography of cassava mosaic viruses in Kenya. J Gen Virol 2006, 87:3053-3065.

15. Qazi J, llyas M, Mansoor S, Briddon R: Legume yellow mosaic viruses: genetically isolated begomoviruses. Mol Plant Pathol 2007, 8:343-348

16. John P, Sivalingam PN, Haq QM, Kumar N, Mishra A, Briddon RW, Malathi VG: Cowpea golden mosaic disease in Gujarat is caused by a Mungbean yellow mosaic India virus isolate with a DNA B variant. Arch Virol 2008, 153:1359-1365.

17. Saunders K, Salim N, Mali VR, Malathi VG, Briddon RW, Markham PG, Stanley J: Characterisation of Sri Lankan cassava mosaic virus and Indian cassava mosaic virus: evidence for acquisition of a DNA B component by a monopartite begomovirus. Virology 2002, 293:63-74.

18. Saunders K, Bedford ID, Stanley J: Pathogenicity of a natural recombinant associated with ageratum yellow vein disease: implications for geminivirus evolution and disease aetiology. Virology 2001, 282:38-47.

19. Rochester DE, Kositratana W, Beachy RN: Systemic movement and symptom production following agroinoculation with a single DNA of tomato yellow leaf curl geminivirus (Thailand). Virology 1990, 178:520-526.

20. Li ZH, Zhou XP, Zhang X, Xie Y: Molecular characterization of tomatoinfecting begomoviruses in Yunnan, China. Arch Virol 2004, 149:1721-1732.

21. Sawangjit S, Chatchawankanphanich O, Chiemsombat P, Attathom T, Dale J, Attathom S: Molecular characterization of tomato-infecting begomoviruses in Thailand. Virus Res 2005, 109:1-8.

22. Patil BL, Dasgupta I: Defective Interfering DNAs of Plant Viruses. Crit Rev Plant Sci 2006, 25:47-64.

23. Patil BL, Dutt N, Briddon RW, Bull SE, Rothenstein D, Borah BK, Dasqupta I, Stanley J, Jeske H: Deletion and recombination events between the DNA$A$ and DNA-B components of Indian cassava-infecting geminiviruses generate defective molecules in Nicotiana benthamiana. Virus Res 2007, 124:59-67.

24. Sunter G, Buck KW, Coutts RH: S1-sensitive sites in the supercoiled double-stranded form of tomato golden mosaic virus DNA component $B$ : identification of regions of potential alternative secondary structure and regulatory function. Nucleic Acids Res 1985, 13:4645-4659. 
25. Orozco BM, Gladfelter HJ, Settlage SB, Eagle PA, Gentry RN, HanleyBowdoin L: Multiple cis elements contribute to geminivirus origin function. Virology 1998, 242:346-356.

26. Ndunguru J, Legg JP, Fofana IBF, Aveling TAS, Thompson G, Fauquet CM: Identification of a defective molecule derived from DNA-A of the bipartite begomovirus of East African cassava mosaic virus. Plant Pathol 2006, 55:2-10

27. Arnim Av, Stanley J: Determinants of tomato golden mosaic virus symptom development located on DNA B. Virology 1992, 186:286-293.

28. Hou YM, Sanders R, Ursin VM, Gilbertson RL: Transgenic plants expressing geminivirus movement proteins: abnormal phenotypes and delayed infection by Tomato mottle virus in transgenic tomatoes expressing the Bean dwarf mosaic virus BV1 or BC1 proteins. Mol Plant Microbe Interact 2000, 13:297-308.

29. Hussain M, Mansoor S, Iram S, Fatima AN, Zafar Y: The nuclear shuttle protein of Tomato leaf curl New Delhi virus is a pathogenicity determinant. J Virol 2005, 79:4434-4439.

30. Rojas MR, Jiang H, Salati R, Xoconostle-Cazares B, Sudarshana MR, Lucas WJ, Gilbertson RL: Functional analysis of proteins involved in movement of the monopartite begomovirus, Tomato yellow leaf curl virus. Virology 2001, 291:110-125

31. Padidam M, Beachy RN, Fauquet CM: Classification and identification of geminiviruses using sequence comparisons. J Gen Virol 1995, 76:249-263.

32. Fauquet CM, Briddon RW, Brown JK, Moriones E, Stanley J, Zerbini M, Zhou X: Geminivirus strain demarcation and nomenclature. Arch Virol 2008, 153:783-821.

33. Ha C, Coombs S, Revill P, Harding R, Vu M, Dale J: Corchorus yellow vein virus, a New World geminivirus from the Old World. J Gen Virol 2006, 87:997-1003.

34. Ha C, Coombs S, Revill P, Harding R, Vu M, Dale J: Molecular characterization of begomoviruses and DNA satellites from Vietnam: additional evidence that the New World geminiviruses were present in the Old World prior to continental separation. J Gen Virol 2008, 89:312-326.

35. Oberste MS, Maher K, Kilpatrick DR, Flemister MR, Brown BA, Pallansch MA: Typing of human enteroviruses by partial sequencing of VP1. J Clin Microbiol 1999, 37:1288-1293.

36. Adams MJ, Antoniw JF, Fauquet CM: Molecular criteria for genus and species discrimination within the family Potyviridae. Arch Virol 2004, 150:459-479.

37. Fauquet CM, Bisaro DM, Briddon RW, Brown JK, Harrison BD, Rybicki EP, Stenger DC, Stanley J: Revision of taxonomic criteria for species demarcation in the family Geminiviridae, and an updated list of begomovirus species. Arch Virol 2003, 148:405-421.

38. Oberste MS, Maher K, Kilpatrick DR, Pallansch MA: Molecular evolution of the human enteroviruses: correlation of serotype with VP1 sequence and application to picornavirus classification. J Virol 1999, 73:1941-1948.

39. de Villiers EM, Fauquet CM, Broker TR, Bernard HU, zur Hausen H: Classification of papillomaviruses. Virology 2004, 324:17-27

40. Karthikeyan AS, Vanitharani R, Balaji V, Anuradha S, Thillaichidambaram P, Shivaprasad PV, Parameswari C, Balamani V, Saminathan M, Veluthambi K: Analysis of an isolate of Mungbean yellow mosaic virus (MYMV) with a highly variable DNA B component. Arch Virol 2004, 149:1643-1652.

41. Brown JK, Idris AM, Ostrow KM, Goldberg N, French R, Stenger DC: Genetic and Phenotypic Variation of the Pepper golden mosaic virus Complex. Phytopathology 2005, 95:1217-1224.

42. Patil BL, Fauquet CM: Cassava mosaic geminiviruses: actual knowledge and perspectives. Mol Plant Pathol 2009, 10:685-701.

43. Ingham DJ, Pascal E, Lazarowitz SG: Both bipartite geminivirus movement proteins define viral host range, but only BL1 determines viral pathogenicity. Virology 1995, 207:191-204.

44. Hatta T, Francki Rl: The fine structure of chloris striate mosaic virus. Virology 1979, 92:428-435.

45. Zhang W, Olson NH, Baker TS, Faulkner L, Agbandje-McKenna M, Boulton Ml, Davies JW, McKenna R: Structure of the Maize streak virus geminate particle. Virology 2001, 279:471-477.

46. Frischmuth $T$, Ringel M, Kocher $C$ : The size of encapsidated singlestranded DNA determines the multiplicity of African cassava mosaic virus particles. J Gen Virol 2001, 82:673-676.
47. Martin DP, Walt van der E, Posada D, Rybicki EP: The evolutionary value of recombination is constrained by genome modularity. PLoS Genet 2005, 1: e51.

48. Walt Evd, Palmer KE, Martin DP, Rybicki EP: Viable chimaeric viruses confirm the biological importance of sequence specific maize streak virus movement protein and coat protein interactions. Virol J 2008, 5:61-72.

49. Gladfelter HJ, Eagle PA, Fontes EP, Batts L, Hanley-Bowdoin L: Two domains of the AL1 protein mediate geminivirus origin recognition. Virology 1997, 239:186-197.

50. Chatterji A, Chatterji U, Beachy RN, Fauquet CM: Sequence parameters that determine specificity of binding of the replication-associated protein to its cognate in two strains of Tomato leaf curl virus-New Delhi. Virology 2000, 273:341-350

51. Chatterji A, Padidam M, Beachy RN, Fauquet CM: Identification of replication specificity determinance in tomato leaf curl virus from New Delhi. J Virol 1999, 73:5481-5489.

52. Garrido-Ramirez ER, Sudarshana MR, Gilbertson RL: Bean golden yellow mosaic virus from Chiapas, Mexico: Characterization, Pseudorecombination with Other Bean-Infecting Geminiviruses and Germ Plasm Screening. Phytopathology 2000, 90:1224-1232.

53. Idris AM, Mills-Lujan K, Martin K, Brown JK: Melon chlorotic leaf curl virus: characterization and differential reassortment with closest relatives reveal adaptive virulence in the squash leaf curl virus clade and host shifting by the host-restricted bean calico mosaic virus. J Virol 2008, 82:1959-1967.

54. Frischmuth T, Roberts S, von Arnim A, Stanley J: Specificity of bipartite geminivirus movement proteins. Virology 1993, 196:666-673.

55. Harrison B, Robinson D: Natural Genomic and Antigenic Variation in Whitefly-Transmitted Geminiviruses (Begomoviruses). Annu Rev Phytopathol 1999, 37:369-398.

56. Ghosh R, Paul S, Das S, Palit P, Acharyya S, Das A, Mir Jl, Ghosh SK, Roy A: Molecular evidence for existence of a New World begomovirus associated with yellow mosaic disease of Corchorus capsularis in India. Australasian Plant Dis Notes 2008, 3:59-62.

57. Padidam M, Beachy RN, Fauquet CM: The role of AV2 ("precoat") and coat protein in viral replication and movement in tomato leaf curl geminivirus. Virology 1996, 224:390-404.

58. Glick E, Zrachya A, Levy Y, Mett A, Gidoni D, Belausov E, Citovsky V, Gafni Y: Interaction with host SGS3 is required for suppression of RNA silencing by tomato yellow leaf curl virus V2 protein. Proc Natl Acad Sci USA 2008, 105:157-161.

59. Harrison B: Advances in Geminivirus Research. Annu Rev Phytopathol 1985, 23:55-82.

60. Briddon RW, Bedford ID, Tsai JH, Markham PG: Analysis of the nucleotide sequence of the treehopper-transmitted geminivirus, tomato pseudocurly top virus, suggests a recombinant origin. Virology 1996, 219:387-394.

61. Etessami P, Watts J, Stanley J: Size reversion of African cassava mosaic virus coat protein gene deletion mutants during infection of Nicotiana benthamiana. J Gen Virol 1989, 70:277-289.

62. Padidam M, Sawyer S, Fauquet CM: Possible emergence of new geminiviruses by frequent recombination. Virology 1999, 265:218-225.

63. Roberts S, Stanley J: Lethal mutations within the conserved stem-loop of African cassava mosaic virus DNA are rapidly corrected by genomic recombination. J Gen Virol 1994, 75:3203-3209.

64. Stanley J, Markham PG, Callis RJ, Pinner MS: The nucleotide sequence of an infectious clone of the geminivirus beet curly top virus. EMBO J 1986, 5:1761-1767.

65. Saunders K, Stanley J: A nanovirus-like DNA component associated with yellow vein disease of Ageratum conyzoides: evidence for interfamilial recombination between plant DNA viruses. Virology 1999, 264:142-152.

66. Tao $X$, Zhou $X$ : Pathogenicity of a naturally occurring recombinant DNA satellite associated with tomato yellow leaf curl China virus. J Gen Virol 2008, 89:306-311.

67. Zhou X, Xie Y, Tao X, Zhang Z, Li Z, Fauquet CM: Characterization of DNAbeta associated with begomoviruses in China and evidence for coevolution with their cognate viral DNA-A. J Gen Virol 2003, 84:237-247.

68. Li Z, Xie Y, Zhou X: Tobacco curly shoot virus DNAbeta Is Not Necessary for Infection but Intensifies Symptoms in a Host-Dependent Manner. Phytopathology 2005, 95:902-908. 
69. Rouhibakhsh A, Malathi VG: Severe leaf curl disease of cowpea - a new disease of cowpea in northern India caused by Mungbean yellow mosaic India virus and a satellite DNA $\beta$. Plant Pathol 2004, 54:259

70. Bull SE, Briddon RW, Sserubombwe WS, Ngugi K, Markham PG, Stanley J: Infectivity, pseudorecombination and mutagenesis of Kenyan cassava mosaic begomoviruses. J Gen Virol 2007, 88:1624-1633.

71. Dry IB, Krake LR, Rigden JE, Rezaian MA: A novel subviral agent associated with a geminivirus: the first report of a DNA satellite. Proc Natl Acad Sci USA 1997, 94:7088-7093.

72. Murant AF, Mayo MA: Satellites of plant viruses. Ann Rev Phytopathol 1982, 20:49-70.

73. Kikuno R, Toh $H$, Hayashida $H$, Miyata T: Sequence similarity between putative gene products of geminiviral DNAs. Nature 1984, 308:562.

74. Saunders K, Bedford ID, Briddon RW, Markham PG, Wong SM, Stanley J: A unique virus complex causes Ageratum yellow vein disease. Proc Natl Acad Sci USA 2000, 97:6890-6895.

75. Briddon RW, Mansoor S, Bedford ID, Pinner MS, Saunders K, Stanley J, Zafar Y, Malik KA, Markham PG: Identification of DNA components required for induction of cotton leaf curl disease. Virology 2001, 285:234-243.

76. Cui X, Li G, Wang D, Hu D, Zhou X: A begomovirus DNA $\beta$-encoded protein binds DNA, functions as a suppressor of RNA silencing, and targets the cell nucleus. J Virol 2005, 79:10764-10775.

77. Saeed M, Zafar Y, Randles JW, Rezaian MA: A monopartite begomovirusassociated DNA beta satellite substitutes for the DNA B of a bipartite begomovirus to permit systemic infection. J Gen Virol 2007, 88:2881-2889.

78. Gilbertson RL, Sudarshana M, Jiang H, Rojas MR, Lucas WJ: Limitations on geminivirus genome size imposed by plasmodesmata and virusencoded movement protein: insights into DNA trafficking. Plant Cell 2003, 15:2578-2591.

79. Mansoor S, Khan SH, Bashir A, Saeed M, Zafar Y, Malik KA, Briddon RW, Stanley J, Markham PG: Identification of a novel circular single-stranded DNA associated with cotton leaf curl disease in Pakistan. Virology 1999, 259:190-199.

80. Sunter G, Bisaro DM: Transactivation of geminivirus AR1 and BR1 gene expression by the viral AL2 gene product occurs at the level of transcription. Plant Cell 1992, 4:1321-1331.

81. Guan C, Zhou X: Phloem specific promoter from a satellite associated with a DNA virus. Virus Res 2006, 115:150-157.

82. Eini O, Behjatnia SAA, Dogra S, Dry IB, Randles JW, Rezaian MA: Identification of sequence elements regulating promoter activity and replication of a monopartite begomovirus-associated DNA $\beta$ satellite. J Gen Virol 2009, 90:253-260.

83. Bao Y, Federhen S, Leipe D, Pham V, Resenchuk S, Rozanov M, Tatusov R, Tatusova T: National center for biotechnology information viral genomes project. J Virol 2004, 78:7291-7298.

84. Swofford D: PAUP User's Manual. Champaign: Illinois Natural History Survey 1991.

85. Sneath PH, Sokal RR: Numerical Taxonomy. San Francisco: W. H. Freeman 1973.

86. Saitou N, Nei M: The neighbor-joining method: a new method for reconstructing phylogenetic trees. Mol Biol Evol 1987, 4:406-425.

\section{doi:10.1186/1471-2148-10-97}

Cite this article as: Briddon et al:: Distinct evolutionary histories of the DNA-A and DNA-B components of bipartite begomoviruses. BMC Evolutionary Biology 2010 10:97.

\section{Submit your next manuscript to BioMed Central and take full advantage of:}

- Convenient online submission

- Thorough peer review

- No space constraints or color figure charges

- Immediate publication on acceptance

- Inclusion in PubMed, CAS, Scopus and Google Scholar

- Research which is freely available for redistribution

Submit your manuscript at www.biomedcentral.com/submit
Biomed Central 